\title{
Entre Experimentos, Controvérsias e Invisibilidades: a constituição do transplante de órgãos como prática terapêutica
}

\author{
Vitor Jasper ${ }^{1}$ \\ ${ }^{1}$ Universidade Federal do Rio de Janeiro, Rio de Janeiro, RJ, Brasil
}

\section{Resumo}

Este artigo pretende realizar a compreensão do processo de constituição do transplante de órgãos como uma prática terapêutica. Partindo dos debates do campo da Antropologia da Ciência e da Técnica, destacam-se alguns elementos que teriam sido fundamentais para o desenrolar desse processo, a saber: a técnica que permite ligar cirurgicamente vasos sanguíneos; os recursos farmacológicos que auxiliam no combate à rejeição do órgão transplantado e os debates acerca do conceito de morte encefálica. Esses elementos, quando agregados, culminaram na construção dessa "descoberta" e permitiram a validação dessa técnica. Tal processo permite compreender o modo de construção de "verdades" de uma disciplina que se pretende universal e tem como objetivo a medicina. Por fim, argumenta-se que esses elementos continuam agenciando o transplante e produzindo efeitos na vida das pessoas.

Palavras-chave: Antropologia da Ciência. Biomedicina. Transplante de Órgãos.

\section{Amidst Experiments, Controversies and Invisibilities: the constitution of organ transplantation as a therapeutic practice}

\begin{abstract}
This article aims to understand the process of constitution of organ transplantation as a therapeutic practice. Based in the field of Anthropology of Science and Technology, we highlight some elements that have been fundamental for the development of this process, namely: the technique that allows the surgical connection of blood vessels; the pharmacological resources that help in the treatment of rejection of the transplanted organ; and the debates on the definition of brain death. These elements together resulted in the construction of this "breakthrough" and helped validate this technique. Revisiting this process enables us to understand how a discipline that is intended to be universal and objective, such as medicine, builds "truths". Finally, we defend that these elements continue to have agency over transplantation and produce effects on people's lives.
\end{abstract}

Keywords: Anthropology of Science. Biomedicine. Organ Transplantation. 


\section{Introdução}

A realização de um transplante de órgãos e de tecidos tende a ser fonte de grande expectativa e incerteza para aqueles que precisam passar pelo procedimento. Para a biomedicina ${ }^{1}$, por sua vez, o transplante é atualmente entendido como uma terapêutica eficaz - mesmo que ainda existam diversas pesquisas sobre o tema e continuamente se busquem novas soluções que diminuam os riscos do procedimento.

Reconhecendo que o transplante de órgãos é uma prática difundida contemporaneamente, o objetivo deste artigo é compreender o seu processo de constituição como prática terapêutica, com o intuito de apontar como cirurgiões e cientistas precisaram consolidar, ao longo do século XX, um corpo de conhecimentos que, quando agregados, permitiram que o procedimento cirúrgico que visa a substituir um órgão "doente" por outro "saudável" passasse a ser entendido como viável e recomendável. Para tanto, tomei como base a compreensão da ciência como atividade social, ao passo que a biomedicina, por sua vez, associada ao discurso científico, propõe um conhecimento centrado no indivíduo e no entendimento do corpo como uma realidade autônoma.

Ainda que o transplante possa ser entendido como técnica, é preciso destacar que não se compreende técnica aqui como um sistema predefinido, mas sim de modo construído e processual. Como Mura (2011) definiu, não é possível abordar a competência técnica somente como desenvolvimento intelectual acumulado, pois ela se constitui a partir de estoques culturais e técnicos, sendo também definida pelo saber-fazer prático. Ao revisitar aquilo que o discurso científico entende como o "acúmulo de conhecimento" que permite o desenvolvimento de uma determinada "técnica", é possível reconhecer um conjunto de visões de mundo que são próprias do saber científico e que são mobilizadas nesse percurso. O processo de construção do conhecimento é, afinal, primordialmente uma atividade social, construído coletivamente e com vínculos históricos (FLECK, 2010).

Uma ressalva adicional é que este artigo tampouco pretende empreender uma reconstituição plena do transplante. Como defende Ludwik Fleck (2010), é impossível conhecer completamente a história de um domínio do saber, visto que se tratam de múltiplas linhas de conhecimento que se cruzam e se entrecruzam; “[...] é como se quiséssemos reproduzir por escrito uma conversa agitada em sua sequência natural, onde várias pessoas falam desordenadamente ao mesmo tempo, sendo que, apesar disso, cristaliza-se uma ideia comum" (FLECK, 2010, p. 56).

Segundo Camargo Jr. (2005), o termo Biomedicina é uma forma de se referir à Medicina Ocidental Contemporânea. Assim, além de ser mais conciso, o autor argumenta que esse termo evidencia a vinculação da racionalidade desse saber com os conhecimentos científicos do campo da Biologia. 
Por isso, o que se propõe aqui é apontar três fatores que foram centrais para o processo de consolidação dessa prática: a técnica que permite ligar cirurgicamente vasos sanguíneos; os recursos farmacológicos que auxiliam no combate à rejeição do órgão transplantado; e os debates acerca do conceito de morte encefálica. Destacar esses fatores é fundamental, uma vez que, como argumentarei, eles continuam a agenciar as experiências terapêuticas das pessoas que realizam um transplante.

É preciso destacar ainda que essa discussão é fruto da minha pesquisa de mestrado (JASPER, 2016). Pensar o processo de constituição do transplante se tornou uma necessidade ao longo do trabalho de campo, realizado em um Serviço de Transplante Hepático. Enquanto eu circulava entre o ambulatório do serviço, as reuniões científicas (encontro semanal de cirurgiões, hepatologistas, residentes e estudantes de medicina) e o setor de internamento, passei a entender o transplante hepático em sua multiplicidade, tendo como referência a orientação praxiográfica proposta por Annemarie Mol ao tratar da aterosclerose (MOL, 2002).

Eu estava interessado particularmente nos encontros entre a equipe do serviço e as pessoas que precisavam realizar o procedimento. Nesses momentos, pude perceber que o desafio desses encontros reside na complexidade do contexto em questão: o transplante é entendido como um último recurso, por se tratar, afinal, de um procedimento cirúrgico com grandes riscos. O que o trabalho de campo gradativamente apontou, porém, é que não é possível reduzir a realização do transplante a uma cirurgia; afinal, há muito mais em jogo: o transplante começa já no processo de inclusão na lista de espera pelo órgão e continua mesmo após seu recebimento. Fazer um transplante implica um rearranjo na vida das pessoas, demandando uma série de cuidados que se estendem por toda a vida da pessoa transplantada.

Fazer o transplante não é "só" passar por um procedimento cirúrgico, justamente porque, em uma cirurgia desse tipo, há todo um encadeamento de ações e de relações que implicam extrapolação do que ocorre no centro cirúrgico. Dessa forma, remontar o processo de constituição do transplante como prática terapêutica é uma maneira de complexificá-lo e de entender como o procedimento é perpassado por um conjunto de práticas.

\section{Abertura: pontos de partida para a análise}

Podemos considerar que a prática do transplante já é bem estabelecida: atualmente, são realizados transplantes de órgãos (coração, fígado, intestino, pâncreas, pulmão, rim) e de tecidos (córnea, medula óssea, pele, ossos). De acordo com dados da Associação Brasileira de Transplantes de Órgãos (ABTO, 2019), no ano de 2019, foram realizados 24.130 transplantes no Brasil².

A biomedicina, detentora do saber que torna possível essa prática, atingiu tal grau de desenvolvimento que lhe permite realizar intervenções que antes pareciam impossíveis, ou que frequentemente eram tratadas como feitos lendários em outros momentos da história. Catão (2010, p. 227), operando com essa oposição entre registros

2 De acordo com os dados fornecidos pela Associação, em 2019, foram realizados 14.943 transplantes de córnea, 6.283 transplantes de rim, 2.245 de fígado, 380 de coração, 173 de pâncreas e 106 de pulmão (ABTO, 2019). 
lendários e início da formação da ciência moderna (esta, não coincidentemente, atrelada ao desenvolvimento da medicina em meados do século XVIII), pontua que "[...] os registros mais antigos desses eventos [transplantes] são da Índia Antiga e da China, onde as escrituras estão repletas de lendas dessa natureza". Esses relatos, ditos lendários (ou milagrosos), são mobilizados muitas vezes para reforçar a ideia de que a medicina teria alcançado realizações que há muito povoam o imaginário social, e que até muito recentemente beiravam o impossível.

De todo modo, essa técnica, tal como realizada atualmente, desenvolve-se dentro de um contexto específico: ela está intrinsecamente ligada a, e retroalimenta, uma certa noção de corpo. Segundo Le Breton (2011), a medicina se configura pelo rigor no estudo do corpo, em uma visão bastante marcada pela filosofia de Descartes. O dualismo cartesiano operaria com uma cisão, rompendo a unidade do homem: de um lado, temos o espírito, responsável pelo pensar; de outro, temos o corpo, uma máquina - dessacralizado e, como realidade à parte, objeto de investigações. O corpo despersonalizado recebe a doença, que é tratada como algo exterior, fruto de causas mecânicas que atingiram seu bom funcionamento. O sujeito e sua história tendem a ser então negligenciados dentro da prática biomédica. Isso permite a Le Breton (2006, p. 71) afirmar que, no mundo moderno, “[...] a possibilidade de retirar e implantar órgãos levanta de modo aguçado a questão dos valores ligados à vida humana e à corporeidade. O corpo é aqui visto como um outro diferente do homem que encarnara".

Le Breton (2011) ressalta que o corpo, para a medicina moderna, tem suas raízes no corpo da anatomia consolidada; em outras palavras, um corpo só remete a si próprio. É na morte, na busca no cadáver dissecado, que a biomedicina encontra respostas para a continuidade de outras vidas, uma vez que a doença, em última instância, está no corpo, em um dos órgãos; logo, o que se apreende em um corpo pode ser aplicado em outro 3 .

A racionalidade da biomedicina pode ser compreendida a partir de três fundamentos: seu caráter generalizante, presente na busca pela produção de discursos que possuam validade universal; seu caráter mecanicista, típico de um saber que pensa o universo como uma máquina que está "subordinada a princípios de causalidade linear traduzíveis em mecanismos"; e seu caráter analítico, dado que a elaboração de tais leis gerais acerca do universo passa, teórica e empiricamente, pelo isolamento das partes - as quais, quando integradas, formam um todo (CAMARGO JR., 2005, p. 179).

Essas características do saber biomédico foram fundamentais para que a prática de transplantes atingisse a proporção e o impacto que tem atualmente. Ainda, a despeito de relatos milenares, o desenvolvimento científico do procedimento está praticamente todo ancorado no século XX. Aqui, seguirei a demarcação temporal de Valter Garcia et al. (2015), que dividem esse desenvolvimento em dois períodos: a fase experimental, entre 1900 e o final de 1940, e a fase clínica, iniciada no final da década de 1940. É importante ressaltar que os relatos biomédicos sobre a história do transplante, especialmente os que abordam seus primeiros 50 anos, parecem não estar interessados em apresentar as

\footnotetext{
Na medida em que Le Breton (2011) entende o corpo como uma realidade simbólica, é preciso destacar que, uma vez que olhamos para o transplante a partir das suas práticas, o interesse também se desloca das concepções simbólicas para as práticas. Assim, seguindo Bruno Latour (2004), não se trata de buscar uma definição para o corpo, mas sim de se voltar para aquilo que o afeta, existindo múltiplas possibilidades de afecção. Isso implica que o corpo se constitui a partir de suas conexões com o mundo.
} 
controvérsias que marcaram esse primeiro período (a "fase experimental"). Ressalvo, assim, que os relatos biomédicos que serão aqui apresentados fazem referência a uma ciência acabada, cujas controvérsias teriam sido superadas, formando uma caixa-preta da qual só sabemos o que entra e o que sai (LATOUR, 2000). Nessa perspectiva, não haveria lugar, ou necessidade, de relatar o contexto, as incertezas e os embates existentes durante aquele período.

\section{A Fase Experimental dos Transplantes: de 1900 até o final de 1940}

Trabalhos que tratam do desenvolvimento científico da técnica dos transplantes (BRADLEY; HAMILTON, 2001; GARCIA et al., 2013a; MIES, 1998; MORDAND, 2007; SILVA, 2008; STEFONI et al., 2004) indicam que a prática passou a ser amplamente pesquisada e aplicada ao longo do século XX. Considerado pioneiro na realização dos transplantes, Emerich Ulmann ${ }^{4}$ relatou, em um Encontro da Sociedade Médica de Viena em 1902, que havia retirado um rim de um cachorro e colocado no pescoço de outro. O rim teria funcionado por cinco dias, tendo produzido urina, que teria sido expelida pelo ureter que estava suturado à pele do animal. Desse modo, considera-se que Ulmann deu início à era dos transplantes, tendo estimulado outros pesquisadores a resolverem o problema das suturas e também o desenvolvimento imunológico (NAGY, 1999).

Outro cirurgião considerado pioneiro, Alexis Carrel $^{5}$, teria sido o responsável pelo desenvolvimento de uma nova técnica de sutura vascular ${ }^{6}$ que teve grande impacto no desenvolvimento dos transplantes, pois as anastomoses ${ }^{7}$ passaram a ser praticadas com redução significativa dos problemas de trombose e de embolia.

Com o surgimento dessa técnica de sutura, iniciou-se o que Valter Garcia et al. (2015) chamaram de fase experimental dos transplantes: diversos investigadores passaram a realizar o procedimento, especialmente em animais (KALLÁS; KALLÁS; KALLÁS, 1999). Nessa época, foram realizados transplantes autólogos (quando se utiliza órgãos e tecidos do próprio beneficiário), alogênicos (transplantes feitos entre seres da mesma espécie) e xenogênicos (modalidade em que doador e receptor são de espécies distintas), sendo que Garcia et al. (2015) não indicam casos de transplantes isogênicos (quando ocorrem entre gêmeos homozigotos).

O próprio Carrel teria se dedicado a realizar experimentos nessa área. Ele publicou, em 1905 (CARREL, [1905] 2001), um artigo em que apresentava seus primeiros resultados cirúrgicos: The Transplantation of Organs: a Preliminary Communication.

$\mathrm{O}$ artigo começa delimitando em que consiste um transplante: a retirada de um órgão e de seus vasos e sua recolocação em outra região, onde eles seriam então unidos às artérias e veias vizinhas. Na sequência, o autor ainda destaca que, nos casos de transplante alogênicos e autólogos, a principal dificuldade encontrada estava na coagulação, pois o

\footnotetext{
4 Emerich Ullmann (1861-1937) nasceu em Pécs, na Hungria.

5 Alexis Carrel (1873-1944) nasceu na França, na cidade de Lyon, e no início do século XX se mudou para os Estados Unidos, onde trabalhou na Universidade de Chicago e no Rockefeller Institute em Nova Iorque.

6 Sutura vascular consiste no ato de ligar cirurgicamente vasos sanguíneos. O próprio Carrel viria a receber um prêmio Nobel em 1912 em reconhecimento do seu trabalho com suturas vasculares e transplantes de órgãos e tecidos.

A anastomose é ligação, natural ou cirúrgica, entre vasos - como artérias e veias - que se comunicam.
} 
órgão transplantado dependia da circulação sanguínea: se os vasos ficassem obstruídos, o órgão gangrenaria. Segundo o autor, esse problema foi praticamente resolvido após o desenvolvimento da nova técnica de sutura, uma vez que ele obteve bons resultados com constância nas operações que realizou em conjunto com o dr. Charles Claude Guthrie.

Carrel também relata dois transplantes que realizara entre 1901-1902. O primeiro foi o transplante da glândula tireoide em um cachorro. Carrel afirma não ter obtido resultados fisiológicos, pois um coágulo teria se formado devido às más condições de assepsia e por questões técnicas da operação. O segundo teria sido um transplante autólogo de rim em um cachorro: ele retirou o rim e o colocou na região do pescoço, tendo suturado a artéria renal à carótida e a veia renal à jugular. Ele detalha que deixara a uretra unida a uma pequena abertura na pele, por onde teria escorrido um fluído claro. Ele ressalta, entretanto, que resultados permanentes não puderam ser observados devido a complicações sépticas. O autor encerra o artigo afirmando que, do ponto de vista clínico, o transplante poderia vir a se tornar uma técnica importante, ainda que mais experimentos em animais devessem ser realizados antes que ela pudesse ser aplicada em pessoas (CARREL, [1905] 2001).

Assim, esses dois transplantes se tratam de suas primeiras tentativas de realização do procedimento. De acordo com Mordand (2007), em 1908, Carrel teria mais uma vez realizado um transplante autólogo renal em um cachorro, e a longa sobrevivência do órgão e do animal - que teria sobrevivido por 28 meses - animaram o cirurgião. Em uma conferência apresentada em 1911, ele comenta o feito:

La interrupción de la circulación sanguínea no habrá durado más que treinta minutos. Con cuatro horas después de la intervención, el animal bebe y deambula. El 19 de febrero, se extrae el riñón derecho. La diuresis es normal: ausencia de albúmina en la orina. En marzo de 1909, la perra da a luz once cachorros y tres más en diciembre del mismo año. En Julio de 1910, el animal, en excelente estado, muere bruscamente debido a una oclusión por vólvulo del intestino delgado. En la autopsia, el riñón es completamente normal tanto por su aspecto y sus vasos como por su vía excretora y su estructura histológica. [...] un trasplante de este tipo no interfiere con las funciones del riñón, incluso después de un largo periodo, y en el plano estrictamente quirúrgico, el trasplante de un órgano se ha hecho realidad. (CARREL, 1911 apud PUERTA, 2006, p. 29-30)

Outros cirurgiões também se dedicavam a essa questão. Stefoni et al. (2004) destacam o trabalho do cirurgião alemão Ernst Unger ${ }^{8}$, que, em 1909, removeu dois rins de um cachorro e os implantou em outro. De acordo com Winkler (1982), esse procedimento foi realizado no dia $1^{\circ}$ de fevereiro; no dia 10 do mesmo mês, o cirurgião exibiu o animal para a Sociedade Médica de Berlim; dois dias depois, para a Sociedade Fisiológica de Berlim. Nesse período, o cachorro estava alerta e urinava. No entanto, no dia 14 de fevereiro, o animal transplantado passou a apresentar vômitos e diarreia, falecendo no dia 18 do mesmo mês. Em dezembro daquele ano, Unger retirou os dois rins de um bebê natimorto e implantou em um símio. O animal faleceu 18 horas após o procedimento e não houve produção de urina; porém, a sutura vascular foi considerada bem-sucedida, uma vez que mesmo o rim não tendo funcionado, o sangue do macaco não coagulou nas

\footnotetext{
8 Ernst Unger (1875-1938) nasceu em Berlim, cidade na qual trabalhou durante sua vida.
} 
veias da criança. No ano seguinte, Unger teria transplantado os rins de um macaco em uma mulher de 22 anos - sem sucesso. Segundo Winkler, em 1910, Ernst Unger já teria realizado aproximadamente cem transplantes de rim, com sobrevivência de até quatro semanas nos casos de transplantes alogênicos.

É fundamental sublinhar que os artigos até aqui apresentados e que tratam dos trabalhos desses cirurgiões tendem a ignorar qualquer tipo de debate ético no que diz respeito aos procedimentos realizados - no máximo, apontam que as pessoas envolvidas nessas pesquisas estavam à beira da morte. Ainda que o campo da bioética tenha se desenvolvido nos anos de 1970 (GARRAFA, 2005), essa é uma questão que salta aos olhos conforme lemos os relatos dos procedimentos e que necessita ser apontada em qualquer análise ulterior, uma vez que se pode entender que, ao se colocar o foco no acúmulo de conhecimento que permitiu o desenvolvimento da técnica, as questões de ordem ética se tornariam secundárias.

De todo modo, pode-se perceber que, nesse momento, a maioria dos relatos encontrados é de transplantes renais. Todavia, esse tipo de transplante não era o único a ser praticado nessas duas primeiras décadas. O próprio Alexis Carrel teria efetuado um transplante de coração em um cachorro. Esses transplantes, em sua maioria, eram heterotópicos9. No que diz respeito ao tipo de transplante, segundo Valter Garcia et al. (2015), exceção feita aos autólogos, os demais não funcionaram e foram abandonados a partir dos anos de 1920.

Apesar disso, Silva (2008) afirma que, entre 1918 e 1920, C. Dederer ${ }^{10}$ teria realizado transplantes isogênicos. O cirurgião teria retirado o rim de um cão e transplantado para outro da mesma ninhada. O cachorro transplantado veio a falecer 28 dias depois do procedimento; porém, o cirurgião avaliou que não houve problema algum com a anastomose e que o rim transplantado passou em testes funcionais, com resultados dentro do esperado para um rim normal. Além de se tratar de um caso de transplante entre gêmeos homozigotos, Silva (2008, p. 146) avalia que "Dederrer (sic) demonstrou em casos de transplantes de rins, que não existe nenhum problema tipo rejeicional quando foram realizados entre gêmeos univitelinos".

Ainda nesse período, teria ocorrido aquele que é considerado o primeiro transplante entre seres humanos (MATEVOSSIAN et al., 2009): em 1933, na Ucrânia, Yuri Voronoy ${ }^{11}$ retirou o rim de um homem que havia morrido em decorrência de um ferimento na cabeça e o colocou em uma mulher que estava com insuficiência renal aguda devido a envenenamento por cloreto de mercúrio. Apesar da cirurgia ter ocorrido sem maiores problemas, dois dias depois, a receptora do órgão faleceu.

Segundo Matevossian et al. (2009), esse transplante não foi bem-sucedido por dois motivos. Primeiramente, havia incompatibilidade no sistema ABO entre doador e receptora: o sangue do doador era do tipo B, e o da receptora, do tipo O. Outra questão foi o tempo em que o órgão ficou sem circulação sanguínea, pois, como na época não

\footnotetext{
9. O transplante é heterotópico quando o enxerto é colocado em uma posição diferente da posição original. O transplante ortotópico, por sua vez, é aquele em que o enxerto é colocado na mesma posição do órgão original.

10 Não foi possível encontrar mais informações sobre este autor. Entretanto, seu trabalho, publicado no Journal of the American Medical Association, em 1918, Studies in the Transplantation of Whole Organs, é frequentemente citado.

11 Yuri Yurijevich Voronoy (1896-1961) nasceu em Poltava, na Ucrânia.
} 
havia o conceito de morte encefálica, o rim foi retirado algumas horas após a parada cardíaca, afetando seu funcionamento.

A leitura que Matevossian et al. (2009) e Silva (2008) fazem do trabalho de Voronoy e de Dederer, respectivamente, já indica qual a próxima questão com que cientistas iriam se ocupar nos próximos anos: o problema da rejeição do enxerto. Nesse sentido, Valter Garcia et al. (2015) observam que, entre o final dos anos de 1930 e o final de 1940, passaram a ser desenvolvidos estudos sobre imunidade, que tiveram sobretudo Peter Medawar ${ }^{12}$ como personagem distinto.

A proeminência de Medawar nesse período se deve às suas pesquisas com transplante de pele para queimados, uma demanda advinda dos campos de batalha da Segunda Guerra Mundial. Segundo Starzl (1995), Medawar conduziu um estudo em que demonstrava que a rejeição da pele se tratava de um fenômeno imunológico. A principal evidência nesses primeiros estudos estava na observação de que os enxertos advindos de um mesmo doador eram rejeitados mais rapidamente conforme as tentativas de transplante eram continuamente realizadas. Silva (2008) afirma que Medawar identificou ainda que, em transplantes entre gêmeos univitelinos, a rejeição não ocorria. Medawar teria atuado também no desenvolvimento de medicamentos para combater esse processo de rejeição, seus trabalhos tendo sido fundamentais para o surgimento de pesquisas que buscavam maneiras de induzir à tolerância aos órgãos transplantados, e que eventualmente levaram ao advento dos medicamentos imunossupressores.

Por tudo isso, esses primeiros 50 anos do século XX ficaram conhecidos na literatura médica como a fase experimental dos transplantes. Em resumo, os feitos mais exaltados nesse período foram a técnica de sutura vascular de Carrel, por resolver um problema cirúrgico comum no início do século - as tromboses dos vasos reconstruídos -, e a descoberta do processo de rejeição por Peter Medawar, que possibilitou o surgimento das drogas imunossupressoras nos anos seguintes.

Apesar de o trabalho científico não poder ser reduzido a feitos individuais, visto que o portador do saber se trata de um coletivo organizado (FLECK, 2010), a bibliografia consultada se esforça em salientar os feitos dos cirurgiões citados ao longo dessa seção, enfatizando sua importância para a história da medicina - e, mais especificamente, para a do transplante. Nesse sentido, Winkler (1982) caracteriza Ernst Unger como um "pioneiro da cirurgia moderna" - mesmo epíteto usado por Sade (2005) para se referir a Alexis Carrel. Starzl (1995), por sua vez, classifica Peter Medawar como "o pai do transplante" e "o Galileu da medicina". Por outro lado, o caso de Alexis Carrel suscita questões de outra ordem - ética. Em 1935, o autor publicou um livro intitulado Man, the Unkown, obra em que defendia ideias eugênicas e misóginas - por exemplo, que pessoas com deficiência não deveriam se reproduzir. Reggiani (2002) observa que Carrel foi um defensor do regime nazista alemão, tendo sido nomeado em 1941, durante a França de Vichy, regente da Fondation Française pour l'Etude des Problèmes Humains - instituição que se notabilizou pela defesa de ideias racistas e higienistas nesse período ${ }^{13}$. Em geral,

\footnotetext{
12 Peter Brian Medawar (1915-1987) nasceu no Brasil, mas teve a cidadania britânica atribuída logo no nascimento, pois sua mãe era cidadã britânica. Ele construiu toda sua carreira na Inglaterra. Em 1960, ele recebeu um Nobel de Medicina pelos avanços na área de imunologia.

13 Entre outras coisas, a Fundação defendia que o governo francês adotasse uma política de controle rigorosa de quais imigrantes deveriam ser admitidos no país, tomando como base quais traços étnicos eram mais desejáveis à "raça" francesa (REGGIANI, 2002).
} 
conforme argumenta Reggiani, cientificamente Carrel estava muito mais preocupado com questões de ordem empírica do que de ordem ética. Nesse sentido, é relevante lembrar que o campo da bioética se desenvolve também com o propósito de ser uma resposta a essa produção eugênica que marcou a primeira metade do século XX.

Em última instância, essa revisão histórica mostra que devemos estar atentos a que tipo de invisibilidade a categoria "experimental" pode gerar quando usada acriticamente. Não é possível aderir a um discurso científico marcado pelas ideias de acúmulo e de avanço e simplesmente desconsiderar não só o contexto dessa "produção que se acumula", mas também suas contradições e controvérsias.

\section{A Fase Clínica dos Transplantes: de 1950 até a contemporaneidade}

Aquilo que costumeiramente se classifica como a fase clínica se constitui como uma das últimas etapas de uma pesquisa médica: a aplicação em seres humanos. No caso do transplante, a fase clínica se inicia a partir do momento em que se colocam em prática formas de controle da rejeição do órgão. Valter Garcia et al. (2015) indicam que essa fase teria se iniciado no final da década de 1940 e início da de 1950, especialmente em Boston e Paris, a partir da utilização da irradiação corporal total como forma de combate à rejeição, tanto com doadores falecidos (morte cardíaca) como com doadores vivos.

Esse período histórico tem certos contornos específicos que merecem destaque. Primeiramente, como salientam Parrilla, Ramírez e Ríos (2008), as necessidades clínicas decorrentes da Segunda Guerra Mundial, um conflito de grandes proporções, implicaram grandes avanços para as ciências médicas. Além disso, especialmente na Europa e nos Estados Unidos, o cenário pós-Segunda Guerra foi marcado por um aumento nos investimentos e no volume de pesquisas em biologia e medicina; houve ainda maior participação do estado nos empreendimentos científicos, ainda que a influência de cada estado em particular fosse limitada pela extensão internacional das pesquisas (QUIRKE; GAUDILLIERE, 2008).

Desse modo, no caso dos transplantes, os primeiros anos da década de 1950 ficaram marcados por um aumento no número de relatos de transplante renal entre humanos ${ }^{14}$. Em um levantamento realizado por Hume et al. (1955), eles identificam quatro grupos de cirurgiões em Paris e em Boston que haviam relatado a realização de transplantes renais nos dois primeiros anos da década de 1950. Adicionalmente, os autores relatam nove casos de transplantes renais que eles próprios haviam realizado entre 1951 e 1952, também em Boston (HUME et al., 1955).

\footnotetext{
${ }^{14}$ Essa proeminência do número de casos de transplantes de rim possui fundamento. Segundo McGeown (1987), o transplante de rim possui diversas vantagens em relação a outros tipos de transplante: o rim é um órgão duplo, o que permite que o transplante seja realizado com doador vivo, o que possibilita o transplante entre irmãos gêmeos, eliminando a necessidade da imunossupressão; além disso, o transplante de rim seria um procedimento mais simples quando comparado com o transplante de coração, pulmão ou pâncreas, por exemplo; o monitoramento do enxerto pode ser feito facilmente pelo volume de urina produzido e por testes sanguíneos; por fim, a função renal pode ser substituída por meios artificiais, como a diálise (apesar de essa técnica só ter sido empregada sistematicamente a partir de meados dos anos de 1960).
} 
Considerando que uma das principais dificuldades enfrentadas naquele período consistia na rejeição do enxerto, os autores informam que, dos nove transplantes conduzidos, seis deles tiveram como terapia imunológica a utilização de ACTH e/ou cortisona. Entretanto, entre os casos descritos, o transplante que teve maior tempo de função renal teria sido realizado sem a utilização de qualquer um dos dois métodos. Isso levou os autores a afirmarem que essas drogas pareciam não exercer qualquer benefício no que dizia respeito à sobrevivência nesse tipo de transplante.

Hume et al. (1955) procuram avaliar também o status do transplante renal em humanos à época. Levando em conta seus estudos e outros disponíveis naquele momento, eles argumentaram ainda não haver lugar para o transplante renal como forma de tratamento terapêutico; seria necessário esperar por resultados de mais estudos conduzidos em animais para que houvesse um maior acúmulo de dados que possibilitasse a resolução dos problemas encontrados, como a compatibilidade entre doadores e a questão da rejeição (HUME et al., 1955).

Apesar das ressalvas colocadas por Hume e seu grupo, a realização de transplantes renais em humanos não foi interrompida. Em 1954, Joseph Murray e John Merrill efetuaram o primeiro transplante renal intervivos com gêmeos homozigotos - eles afirmam que estudos anteriores justificavam a decisão. Uma parte desse conhecimento vinha de pesquisas com transplantes de pele, que haviam definido que tecidos poderiam ser intercambiados entre esses gêmeos sem que houvesse rejeição. Dessa forma, em posse desse conhecimento e com o estágio corrente de desenvolvimento da técnica cirúrgica, os médicos decidiram propor a realização do transplante ao tomarem conhecimento do caso de um jovem de 24 anos com falência renal que possuía um irmão gêmeo homozigoto. No dia 23 de dezembro, os cirurgiões retiraram o rim esquerdo de Ronald H. e o implantaram em seu irmão, Richard H.

No artigo em que apresentam o caso, publicado nove meses depois da cirurgia, Murray, Merrill e Harrison ([1955] 2001) declararam ter sido um "transplante renal bemsucedido", defendendo que o êxito da cirurgia e a sobrevivência do enxerto demonstravam que o transplante renal era um procedimento tecnicamente viável. Conforme aponta McGeown (1987), Richard H. veio a falecer oito anos após o procedimento por conta da mesma doença que o acometera antes do transplante e que levou mais uma vez à falência renal. O mesmo autor relata que, nos anos seguintes, diversos centros na Europa e nos Estados Unidos realizaram transplantes entre gêmeos homozigotos.

Esse transplante feito por Murray e sua equipe é considerado um marco importante, pois a partir de então o transplante de órgãos passou a ser visto como uma prática terapêutica possível. Entretanto, como ressaltou McGeown (1987), poucas pessoas nessa situação clínica eram, ou são, bem-aventuradas a ponto de possuírem um irmão gêmeo a quem recorrer. Portanto, a consolidação dos transplantes como prática terapêutica continuava a passar pela resolução do processo de rejeição.

No final da década de 1950, o método de irradiação total do corpo do receptor passou a ser usado no pré-transplante como forma de imunossupressão. A equipe de Murray em Boston teria realizado 12 transplantes usando essa técnica de imunossupressão, sendo que em 11 casos os transplantados faleceram no primeiro mês após o procedimento. No entanto, em um desses 12 transplantes, realizado em 1959, o receptor sobreviveu até 
1976. Essa técnica foi empregada, na mesma época, pela equipe de Jean Hamburguer, em Paris, onde também tiveram sucesso em um dos casos: um transplante também realizado em 1959 em que o receptor do órgão sobreviveu por 26 anos. Os dois transplantes bem-sucedidos foram feitos com doadores vivos e, nos dois casos, com irmãos gêmeos dizigóticos. Apesar desses dois relatos, os altos riscos envolvidos e a imprevisibilidade da eficiência da irradiação fizeram com que essa forma de imunossupressão fosse abandonada nos anos seguintes (STARZL, 1978).

Nesse sentido, Coelho, Ribar e Saitovitch (2010) relatam que, em 1959, Robert Schwartz e William Dameshek publicaram um trabalho em que descrevem a utilização de um novo medicamento chamado 6-Mercaptopurina (6-MP), que teria sido testado em coelhos e se mostrado eficiente no combate à rejeição. Em 1960, o cirurgião René Küss, após realizar um transplante renal utilizando a irradiação no pré-transplante e, dois meses após o procedimento, diagnosticar que a receptora do rim estava com rejeição, deu a ela o 6-Mercaptopurina; o rim, então, manteve-se funcional por mais oito meses. Com 18 meses, a pessoa que recebeu o transplante veio a falecer.

Em 1960, Roy Calne pesquisava derivados do 6-mercaptopurina, sendo que um desses derivados, a Azatioprina, apresentou melhores resultados. Segundo Coelho, Ribar e Saitovitch (2010), essa nova droga era menos tóxica e apresentava resultados mais prolongados, levando à substituição do medicamento anterior.

Esses autores informam que os primeiros transplantes que utilizaram a Azatioprina foram feitos pela equipe de Joseph Murray, em Boston. Murray e seus colaboradores publicaram em 1963 um artigo em que relatavam 13 casos de transplantes de rim que haviam sido realizados pela equipe entre 1960 e 1963. Desses 13 transplantes, a equipe utilizou a Azatioprina em 11 deles como forma de combate à rejeição. Além disso, em nenhum dos 13 casos foi utilizada a irradiação no pré-transplante (MURRAY et al., 1963). Nesse mesmo artigo, Murray e seus colaboradores relatam a realização de um transplante renal com doador falecido, ocorrido em 1962, em que o receptor ainda estaria vivo e com boa função renal quando ocorreu a publicação do artigo (MURRAY et al., 1963).

Coelho, Ribar e Saitovitch (2010) consideram que esse foi o primeiro transplante renal com doador falecido com sucesso prolongado. Apesar de esse transplante ser considerado um marco, os autores finalizam o artigo de maneira cautelosa. Eles reconhecem que os resultados alcançados pareciam impossíveis dez anos antes, mas afirmam que é preciso pensar a logística envolvendo o transplante, ou seja, maneiras de obtenção e manutenção do órgão doado. Além disso, eles questionam a eficácia do medicamento contra rejeição a longo prazo, pois não se sabia por quanto tempo a droga deveria ser administrada e se o risco de rejeição diminuiria com o passar dos anos (MURRAY et al., 1963).

Coelho, Ribar e Saitovitch (2010) denominam esse período como a "era da azatioprina". Os autores afirmam que é a partir desse momento que os transplantes passaram a obter bons resultados. Eles afirmam que, em 1965, a sobrevivência média de um ano para transplantados renais era de $80 \%$ para quem tinha recebido órgão de doador vivo, e de $65 \%$ para quem o recebera de doador falecido.

É interessante observar que a técnica se difundiu a ponto de surgir uma nova forma de avaliação da eficácia dos transplantes: dados estatísticos. Trata-se de um marco 
importante nesse processo aqui apresentado, uma vez que, como argumenta Tesser (2007, p. 471) sobre a importância dos estudos quantitativos para a medicina,

A validação e estabelecimento das verdades vão migrando do dia-a-dia dos tratamentos e evoluções dos doentes reais, das casuísticas dos médicos, progressivamente para o âmbito dos estudos científicos de validação das intervenções, tipicamente os ensaios clínicos controlados e os estudos de coortes.

Com isso, estamos diante de um indicativo de que o transplante estaria ainda mais próximo da clínica, logo de ser aplicado como prática terapêutica - o que não necessariamente significa que ele esteja, naquela época ou ainda hoje, apartado do laboratório. Essa mudança ocorreu, como destacam Parrilla, Ramírez e Ríos (2008), já que o desenvolvimento da imunossupressão permitiu que o transplante se constituísse como uma realidade clínica. Além disso, ele foi responsável pelo que os autores chamaram de "efeito multiplicador": esforços proliferaram por diversas áreas. Os autores evidenciam algumas: na área cirúrgica e anestésica, esforços para transplantar outros órgãos; nas ciências básicas (imunologia, microbiologia, farmacologia, etc.), pesquisas sobre a rejeição e modos de diagnosticar e combater infecções; buscam-se formas para superação do número limitado de doações de órgãos; e, por fim, aumento da procura por maneiras de conservar os órgãos que seriam utilizados para transplante.

Considera-se que o transplante dos demais órgãos teve início, assim, a partir de 1963. Se Paris e Boston eram centros de desenvolvimento para o transplante renal, Denver e Cambridge se tornaram centrais para o transplante hepático, e a Cidade do Cabo e Stanford, para o transplante cardíaco. Em 1963, Thomas Starzl liderou o primeiro transplante hepático na Universidade do Colorado, em Denver; em 1967, ocorreu o primeiro transplante de coração, conduzido por Christiaan Barnard na Cidade do Cabo, África do Sul.

Como já afirmado, a difusão dos transplantes gerou maiores esforços para controle da rejeição. A azatioprina foi fundamental para esse processo. Entretanto, tratava-se de um método de imunossupressão não específico, uma vez que ele aniquila a atividade do sistema imunológico independentemente de qual seja o antígeno em ação ${ }^{15}$. Por isso, o medicamento facilitava o surgimento de infecções oportunistas, já que a capacidade de defesa do sistema imune estaria reduzida.

Em 1976, o imunologista belga Jean-François Borel, pesquisando novos antibióticos, apresentou um polipeptídeo cíclico que possuía efeito inibitório seletivo em linfócitos. Esse polipeptídeo foi denominado ciclosporina. Realizando um bloqueio seletivo, atuando principalmente no que concerne às atividades das células $\mathrm{T}$, a ciclosporina se tornou o imunossupressor específico mais utilizado nos transplantes a partir da década de 1980, quando se tornou disponível para uso comercial (TEIXEIRA; REZENDE, 2004).

Ainda de acordo com Teixeira e Rezende (2004), a ciclosporina trouxe um grande avanço para a realização dos transplantes. Por outro lado, a ciclosporina possui efeitos colaterais, como hipertensão arterial refratária, diabetes, nefrotoxicidade e hepatotoxicidade. Portanto, normalmente ela não é utilizada isoladamente, pois empregá-la junto de outros medicamentos, como a prednisona ou a azatioprina, possibilita reduzir sua dosagem.

15 Antígenos são substâncias que desencadeiam uma resposta imune do organismo, levando à produção de anticorpos. 
A literatura indica que existem três tipos de rejeição: hiperaguda, aguda e crônica. A rejeição hiperaguda pode ocorrer nas primeiras 24 horas após o procedimento cirúrgico; a aguda, no período de dias ou semanas após o transplante; e a crônica, meses ou anos depois da cirurgia. Os fármacos mencionados trouxeram bons resultados para a rejeição aguda; todavia, ainda estariam associados a efeitos adversos, tanto agudos quanto crônicos, como riscos cardiovasculares e dano progressivo ao órgão transplantado, o que fez com que o resultado do transplante a longo prazo não se desenvolvesse como esperavam os especialistas (GARCIA et al., 2013b).

Desse modo, apesar do emprego de novos medicamentos, a rejeição ainda é uma realidade a ser enfrentada tanto pela equipe quanto - e principalmente - pelos transplantados, de tal modo que as atividades desempenhadas nos serviços de transplante, após a realização do procedimento cirúrgico, passam em grande medida pelo monitoramento do controle da rejeição e dos possíveis efeitos dos medicamentos imunossupressores. Essa necessidade de cuidados médicos regulares, por sinal, é significativa para que se compreenda a experiência no pós-transplante (JASPER, 2016).

Com o avanço nas pesquisas sobre os medicamentos imunossupressores, outro aspecto de grande impacto na consolidação da prática do transplante foi o estabelecimento da definição de morte encefálica ${ }^{16}$. Em 1968, um Comitê $A d H_{o c}{ }^{17}$ foi organizado na Universidade de Harvard com o intuito de definir os critérios para o que viria a ser considerado como morte encefálica. Segundo Lazzaretti (2008), esse grupo era composto de dez médicos, um historiador, um advogado e um teólogo.

De acordo com o documento elaborado pelo Comitê, seu objetivo era definir o coma irreversível como um novo critério para morte. Isso teria sido motivado por duas razões. A primeira seria as condições que possibilitaram melhora nas medidas de ressuscitação e de manutenção da vida - por exemplo, o surgimento do ventilador mecânico, que permitiu novos esforços para casos de ferimentos severos; apesar de esses avanços eventualmente garantirem que o coração continuasse funcionando, era possível que, em algumas situações, a atividade cerebral estivesse permanentemente comprometida de tal modo que não seria possível recuperar casos de comas irreversíveis mesmo com essas novas medidas. A segunda razão seria que critérios considerados obsoletos para definição de morte decorriam em controvérsias na obtenção de órgãos para o transplante (AD HOC COMMITTEE OF THE HARVARD SCHOOL, 1968).

A partir dessas motivações, o Comitê procurou definir quais deveriam ser esses critérios para que o conceito de morte encefálica fosse adotado de maneira uniforme. Como salienta Macedo (2008), os critérios definidos pelo Comitê supracitado passaram a ser questionados por outros grupos de pesquisadores, abrindo, assim, um espaço de discussão que suscitou em outros critérios para determinação da morte encefálica. Apesar da falta de consenso, a autora entende que todas as controvérsias em torno da questão

\footnotetext{
16 Neste artigo adoto a tradução de brain death como morte encefálica. Como argumentam Egea-Guerrero, Revuelto-Rey e Gordillo-Escobar (2012), apesar de comumente morte cerebral e morte encefálica serem usadas como sinônimos, esse uso é impreciso. De acordo com os critérios avaliativos contemporâneos, a definição da morte encefálica se refere à interrupção tanto da função cerebral quanto do tronco encefálico, enquanto somente a perda da função cerebral, tendo em vista que o cérebro corresponde a uma porção do encéfalo, não é mais classificada como morte.

17 É relevante ressaltar que, entre os médicos que fizeram parte do Comitê, encontram-se John Merrill e Joseph Murray, cirurgiões já citados neste trabalho e que têm seus nomes ligados à história dos transplantes.
} 
não foram suficientes para abrir essa caixa-preta (LATOUR, 2000), ou seja: ninguém teria provado que o coma irreversível dentro dos parâmetros estabelecidos não significava morte. Dessa forma, ainda que essas controvérsias tenham resultado em alterações nos parâmetros avaliadores da morte encefálica, o conceito de morte encefálica se tornou o critério para definição de morte, com status de verdade (MACEDO, 2008).

Pensando pragmaticamente sobre esse conceito, Margaret Lock $(2000 ; 2002)$ realizou um estudo comparativo com médicos intensivistas nos Estados Unidos e no Japão, procurando investigar o conceito de morte encefálica e as construções em torno dessa concepção que surgem das práticas desses profissionais. Um dos principais pontos destacados pela autora é que, no Japão, a pessoa diagnosticada com morte encefálica ainda é considerada uma pessoa viva. No caso estadunidense, a autora argumenta que, para os intensivistas, o corpo com morte encefálica estaria vivo, mas a alma já não mais habitaria esse corpo.

Macedo (2008) afirma que a morte encefálica é um conceito moderno construído pela medicina, e que possui um caráter ambíguo, fluído, flexível e liminar. A autora se propôs a verificar o que os médicos brasileiros pensavam sobre tal conceito. De acordo com os médicos entrevistados por ela, a morte encefálica seria uma morte técnica, em contraposição à morte "natural" provocada pela parada cardíaca. Para dar conta do caráter liminar e ambíguo da morte encefálica, e influenciada pelo trabalho de Lock, a autora denomina aquele nesta condição como um cadáver-vivo - forma encontrada para evidenciar que já não se trata mais de uma pessoa, mas também não é um cadáver, pois o coração ainda funciona.

Margaret Lock (2000), assim como Juliana Macedo, salienta a relação entre a morte encefálica e a doação de órgãos - debate estimulado pelo próprio documento do Comitê de Harvard. Lock afirma que, após a realização do primeiro transplante cardíaco em 1967, a questão acerca de uma nova definição de morte precisava ser urgentemente respondida, pois mais de um cirurgião teria sido acusado de homicídio por remover para transplante um coração que ainda batia.

Essa relação entre o transplante de órgãos e a morte encefálica se estende para além da motivação teórica ou filosófica, envolvendo também o desenvolvimento do conceito a partir de necessidades práticas para a realização da operação. Afinal, uma das características do transplante de órgãos (fígado, pulmão, pâncreas, coração) é que eles devem ser retirados antes que haja a parada cardíaca - em outros termos, antes que seja interrompido o fluxo sanguíneo ${ }^{18}$.

Assim, o transplante depende diretamente do conceito de morte encefálica, pois, como enfatiza Lock (2000), por mais que frequentemente se coloque que o debate deva ser realizado independentemente da questão da procura por órgãos, a relação já estava colocada desde o início. A autora argumenta, ainda, que a crise gerada pelo baixo número de órgãos fez com que se travasse uma busca por outras fontes; nessa empreitada, a redefinição da morte teve grande impacto, pois permitiu que pessoas em estado vegetativo permanente, a depender de certos critérios, fossem consideradas mortas e se tornassem doadoras.

18 No caso do rim, o órgão poderia ser retirado até 30 minutos depois da parada cardíaca. 
Lock (2000) afirma que, nos Estados Unidos, o conceito de morte encefálica já está consolidado, de modo que, prestados os devidos respeitos pelo falecimento da pessoa, há a expectativa de que a família autorize a doação dos órgãos de seu parente falecido - dando aos que serão "captados" a alcunha simbólica de "dádiva da vida". No caso japonês, em contrapartida, a situação é significativamente diferente. De acordo com Kiuchi e Tanaka (2003), na época da publicação do artigo, 99\% dos transplantes hepáticos no Japão eram realizados com doadores vivos. Lazzaretti (2008) ressalta ainda que, mesmo no contexto brasileiro, o momento de pedido de captação do órgão envolve uma questão delicada: nem sempre o diagnóstico de morte encefálica é bem aceito pelos familiares do possível doador, já que, ainda que se trate de uma pessoa clinicamente considerada morta, ela ainda respira (por conta do respirador artificial) e o coração ainda bate.

Desse modo, é impossível tratar da técnica do transplante sem abordar o tema da morte encefálica. Como temos buscado ressaltar, a implicação social da sua conceptualização foi um dos fatores que propiciaram que os transplantes atingissem o status de prática terapêutica; assim como Macedo (2008, p. 125) sugere, "[...] tanto a morte encefálica como os transplantes de órgãos são lados da mesma moeda".

Macedo ressalta ainda que uma das distinções entre intensivistas e médicos das equipes de transplante é que, para os primeiros, a morte encefálica representava um duplo fracasso - seria preciso lidar com o fracasso da morte de um paciente e ainda cuidar do "cádaver-vivo" -, enquanto para as equipes de transplante, a morte encefálica estaria atrelada à ideia de vitória, uma vez que ela propicia que vidas sejam salvas.

Durante o trabalho de campo realizado para a dissertação, o tema da morte encefálica apareceu de maneira específica. As vezes que o termo foi citado ocorreram quando os médicos relatavam o tempo transcorrido entre a morte encefálica e a captação do fígado para transplante - ou seja, falava-se da morte-técnica. De maneira indireta, o tema aparecia quando os profissionais da equipe e os transplantados comentavam sobre a falta de incentivo à doação de órgãos, assim como de políticas que promovessem a educação sobre o tema - o que, como também ressaltou Macedo, indiretamente significa defender a divulgação do conhecimento sobre a morte encefálica.

A regulação do processo de captação e de doação de órgãos é dotada de toda uma organização específica. Como foi possível acompanhar no serviço de transplante hepático em que realizei a pesquisa, uma vez determinada a necessidade de uma pessoa realizar o transplante, a equipe do serviço efetua o cadastro dessa pessoa junto à Central de Notificação, Captação e Distribuição de Órgãos (CNCDO) do estado. Cabe à Central coordenar as inscrições dos receptores nas listas. Ao mesmo tempo, quando uma pessoa tem morte encefálica, é preciso notificar a $\mathrm{CNCDO}$, que verifica para onde o órgão irá e providencia o transporte.

A organização da lista de espera do transplante hepático não é definida pela ordem de inscrição na lista, mas sim por critérios clínicos. A classificação é baseada no Model End Liver Disease (MELD), que, a partir de um conjunto de exames clínicos, estabelece uma pontuação que determina um valor de referência para a gravidade da doença hepática. Como salienta Machado (2011), a adoção da escala MELD foi motivada pela alta mortalidade entre as pessoas que estavam na fila de espera do transplante e permitiu que pessoas em situação agravada realizassem o transplante antes. Isso também impacta 
na organização do Serviço, uma vez que, dado que os exames usados para essa avaliação devem ser renovados e enviados para a central com regularidade, as pessoas que estão aguardando pelo órgão e a equipe do serviço devem se manter em contato.

De toda forma, apesar do esforço em organizar e melhor regular a doação de órgãos, dados da Associação Brasileira de Transplantes de Órgãos (ABTO) apontam para a discrepância ainda existente entre o número de pessoas que precisam realizar um transplante no Brasil e o número de órgãos doados: ao longo de 2019, foram realizados 24.130 transplantes; apesar disso, em dezembro do mesmo ano, havia 37.946 pessoas em lista de espera (ABTO, 2019) ${ }^{19}$. Por esse motivo, a questão da disponibilidade de órgãos se mantém como uma questão central. Ainda que o transplante tenha se tornado uma prática terapêutica - ou seja, chegado à clínica -, isso não significa que novas perguntas e problemas deixaram de surgir, como: a produção de órgãos biônicos e a possibilidade de realização de xenotransplantes como formas de superação da escassez de órgãos para doação; o aprofundamento de dilemas éticos referentes ao conceito de morte e ao consentimento para doação de órgãos; assim como a existência de mercados ilegais associados ao tráfico de órgãos para transplante.

Ainda que o impacto desses três fatores centrais que destaquei para a consolidação da técnica sejam visíveis nas práticas do transplante, é interessante observar como eles são obliterados do debate: a ciência tende a invisibilizar seu próprio processo de construção, optando por destacar a ideia de "descoberta" e proclamando sua pretensa neutralidade. Como afirmou Latour (2000), a ciência possui duas faces: a que não sabe e a que já sabe. A primeira é a ciência em construção; a segunda é a ciência pronta, acabada. A "descoberta" é o resultado dessa ciência pronta. Ela nos demanda que acatemos aos fatos sem discuti-los, pois a verdade sempre se sustenta e nos indica o que fazer. Essa ciência recorre à ideia de Natureza como forma de encerrar qualquer discussão, qualquer controvérsia, pois "nela reside a verdade" (LATOUR, 2000). Conforme lemos os relatos sobre a história do transplante, parece que nos aproximamos do fim do processo que culmina na construção desse "fato" que é o transplante como prática terapêutica. Isso corresponde ao modo de construção de "verdades" de uma disciplina que se pretende universal e objetiva. Entendemos assim que a constituição dessa prática terapêutica requereu que algumas caixas-pretas fossem fechadas: as técnicas de sutura, os imunossupressores e a morte encefálica.

Essa discussão, contudo, não se encerra como somente resultado de certas circunstâncias: é fundamental compreender o processo de construção do transplante como algo que também gera efeitos e é, em última instância, produtivo.

Nesse sentido, vale salientar que a técnica do transplante não possui um fim em si mesma. Isso é demonstrado no momento em que a técnica passa a ser aplicada como prática terapêutica, quando inclusive passa a ser financiada pelo estado nacional brasileiro. Do mesmo modo, o que ocorre dentro do centro cirúrgico não permite uma compreensão global do fenômeno: após passar por um procedimento de alto risco, para além do impacto físico, é preciso lidar, como identificamos anteriormente (JASPER, 2016), com os efeitos

\footnotetext{
19 Os dados fornecidos pela Associação apontam que 25.163 aguardavam um transplante de rim, 1.178 de fígado, 276 de coração, 187 de pulmão, 383 de pâncreas e rim, 18 de pâncreas e 10.741 estavam em lista de espera por um transplante de córnea (ABTO, 2019).
} 
subjetivos de viver com um órgão que pode ser compreendido como uma metonímia do seu doador, gerando uma mudança ontológica para o receptor. Ademais, as pessoas que realizam um transplante devem se adequar a uma nova forma de organização de suas vidas, visto que é preciso um cuidado permanente - que passa pelo uso contínuo de imunossupressores e visitas regulares ao ambulatório do serviço de transplante - que se estenderá por toda a vida.

Assim, apresentar parte da construção desse fato científico não parece suficiente para o encerramento da discussão acerca do que é um transplante, uma vez que inviabilizaria uma visão abrangente e complexa sobre o tema: é preciso abordá-lo de maneira simétrica questionando a distinção entre natureza e cultura. O transplante, como alertou Latour (1994) a respeito das práticas modernas, opera tanto por meio do trabalho de purificação quanto do de mediação - práticas distintas, mas inter-relacionadas, e que são a marca da modernidade.

O trabalho de mediação é responsável pela produção dos híbridos - misturas de natureza e de cultura que criam novos seres - e é feito por nós, por meio de nossas práticas. Entretanto, Latour assinala que o trabalho de mediação não seria reconhecido pelos modernos. Nesse sentido, quando reduzimos o transplante a uma técnica cirúrgica (processo de purificação), perdemos de vista os arranjos que ocorrem tanto para que a prática venha a ser aplicada, como as associações e os desenvolvimentos decorrentes da sua aplicação, invisibilizando, assim, o processo de mediação.

É precisamente o processo de purificação que nega a produção desses híbridos, já que cria duas zonas ontológicas distintas; os híbridos são reduzidos ora para a natureza, ora para a cultura. Esse processo implica a concepção de que as leis da natureza não são controladas pelos humanos, mas podem ser reproduzidas nos laboratórios. Tal distinção permite, então, que o processo de construção da natureza seja apresentado como descoberta. Para os modernos, somente o processo de purificação teria validade, sendo reconhecido e legitimado (LATOUR, 1994).

Em vista disso, o transplante, se reduzido a uma técnica científica, não permite que se compreenda o que é essa prática, uma vez que a abordagem tecnicista está atrelada ao seu processo de purificação. Assim, mesmo que comumente essa prática seja designada como a substituição de um órgão por outro, ainda há uma série de outras implicações e de outros fatores que a integram e que são vivenciados tanto pela equipe que atua em um serviço de transplante quanto por aqueles que passam, direta ou indiretamente, pelo procedimento cirúrgico. Além do impacto decorrente da discrepância do número de órgãos para doação em relação ao número de pessoas que necessitam do procedimento, sabe-se que, por mais desenvolvida que a técnica cirúrgica seja, ainda se trata de uma cirurgia de risco. Ao mesmo tempo, no pós-transplante, os cuidados necessários para que não haja rejeição do novo órgão são um fator central na relação entre equipe e transplantados, pois devem se estender por toda a vida da pessoa transplantada. Dessa maneira, certo da ineficiência da explicação "natural", defendo a abertura e a ampliação do que se considera ser o transplante, um entendimento expandido que considere os impactos gerados nas vidas das pessoas que passam por tal procedimento. 


\section{Considerações Finais}

Neste artigo, tive por objetivo apresentar parte do processo de construção do transplante como uma prática terapêutica. Procurei demonstrar a estabilização de três elementos que foram fundamentais para que o transplante se tornasse uma técnica aplicável com fins terapêuticos: o desenvolvimento da técnica de sutura vascular, que permitiu a substituição cirúrgica de um órgão por outro; o combate à rejeição do novo órgão, com a produção de medicamentos imunossupressores; e, por fim, a elaboração do conceito de morte encefálica, que possibilitou que houvesse órgãos disponíveis para a realização do procedimento.

É possível perceber como a viabilização de cada elemento tem relação com o desenvolvimento do outro. Assim, quando se tornou possível a substituição cirúrgica dos órgãos, tornou-se necessário encontrar uma maneira de que esse órgão não fosse rejeitado pelo novo organismo. Do mesmo modo, o combate à rejeição potencializou as possibilidades desse tratamento, mas ainda não havia um número de órgãos suficientes - e, no caso de transplantes como o de coração e o de fígado, era preciso que o órgão do doador fosse removido enquanto ainda houvesse fluxo sanguíneo.

Certamente esses três elementos não foram os únicos que possibilitaram a realização dos transplantes, mas julgo aqui que eles assumiram grande preponderância nesse processo. Mas é preciso estar atento aos efeitos dessa concepção de encadeamento dos elementos: ela traz em seu bojo a ideia de que o conhecimento se acumula e de que os debates e os problemas estariam superados, o que funciona como uma forma de apagamento, tanto das controvérsias como também dos agenciamentos desses elementos nas práticas atuais.

As suturas, por mais bem definidas cientificamente que estejam, ainda representam uma possível complicação após o procedimento. Do mesmo modo, como verifiquei ao longo do trabalho de campo, as técnicas imunossupressoras são um elemento fundante da relação entre equipe e transplantados. Por fim, não menos importante, está a questão da morte encefálica, visto o profundo impacto da contínua escassez de órgãos na organização das atividades do Serviço de Transplante Hepático estudado. Assim, esses elementos continuam agenciando o transplante e produzindo efeitos na vida das pessoas.

Dessa forma, o transplante, assim como as demais práticas modernas, se constitui tanto pelo trabalho de mediação quanto pelo de purificação (LATOUR, 1994). Entretanto, o processo de purificação do transplante faz com que o compreendamos como um processo técnico, constituído cientificamente. O trabalho de mediação, por outro lado, é o que permite pensar nas implicações de passar por tal procedimento, uma vez que ele produz híbridos, mistos de natureza e cultura. A partir disso, argumentei que a constituição de uma técnica terapêutica não representa um fim, uma realidade em si, mas sim aponta para um processo de abertura que, no caso do transplante, significa enfatizar a forma como o procedimento é vivido pelas pessoas envolvidas. 


\section{Referências}

ABTO - ASSOCIAÇÃO BRASILEIRA DE TRANSPLANTES DE ÓRGÃOS. Dimensionamento dos Transplantes no Brasil e em cada estado (2012-2019). Registro Brasileiro de Transplantes, [s.l.], ano XXV, n. 4, 2019.

AD HOC COMMITTEE OF THE HARVARD SCHOOL. A definition of irreversible coma: report of the Ad Hoc Committee of the Harvard School to examine the definition of brain death. Journal of the American Medical Association, [s.l.], v. 204, n. 6, 1968.

BRADLEY, John Andrew; HAMILTON, David. Organ Transplantation: an Historical Perspective. In: HAKIM, Nadel; DANOVITCH, Gabriel (org.). Transplantation Surgery. London: Springer, 2001.

CAMARGO JR., Kenneth Rochel de. A Biomedicina. PHYSIS: Rev. Saúde Coletiva, Rio de Janeiro, v. 15, (Suplemento), p. 177-201, 2005.

CARREL, Alexis. The Transplantation of Organs: A Preliminary Communication. Yale Journal of Biology and Medicine, [s.l.], v. 74, n. 4, p. 239-241, [1995] 2001.

CATÃO, Marconi do Ó. A Moderna Tecnologia Médica dos Transplantes e o Ordenamento Jurídico Brasileiro. Revista Datavenia, [s.l.], v. 1, p. 225-241, 2010.

COELHO, Juliano Cé; RIBAR, Julia; SAITOVITCH, David. Transplante renal: do imaginário à sua real aplicação médica. In: GUILHERMANO, Luiz Gustavo et al. (org.). Páginas da História da Medicina. Porto Alegre: EDIPUCRS, 2010. p. 123-131.

EGEA-GUERRERO, Juan Jose; REVUELTO-REY, Jaume; GORDILLO-ESCOBAR, Elena. Muerte cerebral no es un término sinónimo de muerte encefálica. Neurología, [s.l.], v. 27, n. 6, p. 377-378, 2012.

FLECK, Ludwik. Gênese e Desenvolvimento de um Fato Científico. Belo Horizonte: Fabrefactum. 2010.

GARCIA, Clotilde Druck et al. Manual de Doação e Transplantes. Rio de Janeiro: Elsevier. 2013a.

GARCIA, Clotilde Druck et al. Terapia Imunossupressora para Transplante de Órgãos. In: GARCIA, Clotilde Druck et al. (Org.). Manual de Doação e Transplantes. Rio de Janeiro: Elsevier, 2013b. p. 149-161.

GARCIA, Valter Duro et al. Situação dos Transplantes no Brasil. In: GARCIA, Clotilde Druck et al. (Org.). Doação e Transplante de Órgãos e Tecidos. São Paulo: Segmento Farma, 2015. p. 43-60.

GARRAFA, Volnei. Introdução à Bioética - An Introduction to bioethics. Revista do Hospital Universitário UFMA, São Luís, v. 6, n. 2, p. 9-13, 2005.

HUME, David Milford et al. Experiences with Renal Homotransplantation in the Human: report of nine cases. The Journal of Clinical Investigation, [s.l.], v. 34, n. 2, p. 327-382, 1955.

JASPER, Vitor. Como pode um fígado fazer tudo isso? Estudo antropológico em um serviço de transplante hepático. 2016. 196f. Dissertação (Mestrado em Sociologia e Antropologia) - Instituto de Filosofia e Ciências Sociais, Universidade Federal do Rio de Janeiro, Rio de Janeiro, 2016.

KALLÁS, Ibrahim Elias; KALLÁS, Alexandre Carvalho; KALLÁS, Elias. Anastomoses arteriais: passado, presente e futuro. Acta Cirúrgica Brasileira, São Paulo, v. 14, n. 4, 1999.

KIUCHI, Tetsuya; TANAKA, Koichi. Liver Transplantation from Living Donors: Current Status in Japan and Safety/Long-Term Results in the Donor. Transplantation Procedings., [s.l.], v. 35, n. 3, p. 1.172-1.173, 2003. 
LATOUR, Bruno. Ciência em Ação: como seguir cientistas e engenheiros sociedade afora. São Paulo: Editora UNESP, 2000.

LATOUR, Bruno. Jamais fomos modernos. Rio de Janeiro: Editora 34, 1994.

LATOUR, Bruno. How to Talk about the Body? The Normative Dimension of Science Studies. Body and Society, [s.l.], v. 10, n. 2-3, p. 205-229, 2004.

LAZZARETTI, Claire Terezinha. O Doador Vivo no Transplante Hepático: a Dádiva na Contemporaneidade. 2008. 240f. Tese (Doutorado em Sociologia) - Setor de Ciências Humanas. Universidade Federal do Paraná, Curitiba, 2008.

LE BRETON, David. A Sociologia do Corpo. Petrópolis: Editora Vozes, 2006.

LE BRETON, David. Antropologia do Corpo e Modernidade. Petrópolis: Editora Vozes, 2011.

LOCK, Margaret. On dying twice: culture, technology and the determination of death. In: LOCK, Margaret; YOUNG, Alan; CAMBROSIO, Alberto (org.). Living and Working with the New Medical Technologies: Intersections of Inquiry. Cambridge: Cambridge University Press, 2000.

LOCK, Margaret. Twice Dead: Organ Transplants and the Reinvention of Death. Berkeley e Los Angeles: University of California Press, 2002.

MACEDO, Juliana Lopes de. A subversão da morte: um estudo antropológico sobre as concepções de morte encefálica entre médicos. 2008. 173f. Dissertação (Mestrado em Antropologia) Instituto de Filosofia e Ciências Humanas, Universidade Federal do Rio Grande do Sul, Porto Alegre, 2008.

MACHADO, Adriana Gonçalves da Silva. Impacto da implantação do escore MELD na alocação de fígados e nos resultados dos transplantes hepáticos: a experiência de um centro brasileiro. 2011. 82f. Dissertação (Mestrado em Medicina) - Universidade Federal de Ciências da Saúde de Porto Alegre, Porto Alegre, 2011.

MATEVOSSIAN, Edouard et al. Surgeon Yurii Voronoy (1895-1961) - a pioneer in the history of clinical transplantation: in Memoriam at the 75th Anniversary of the First Human Kidney Transplantation. Transplant International, [s.l.], v. 22, p. 1.132-1.139, 2009.

MCGEOWN, Mary Graham. Transplantation. The Ulster Medical Journal, [s.l.], v. 56, p. 79-86, 1987.

MIES, Sergio. Transplante de Fígado. Revista da Associação Médica Brasileira, [s.l.], v. 44, n. 2, p. 127-134, 1998.

MOL, Annemarie. The body multiple: ontology in medical practice. Durham and London: Duke University Press, 2002.

MORDANT, Pierre. La transplantation d'organe - Petite histoire d'une grande aventure. Info Respiration, [s.l.], n. 82, p. 27-31, 2007.

MURA, Fabio. De sujeitos e objetos: um ensaio crítico de Antropologia da Técnica e da Tecnologia. Horizontes Antropológicos, UFRGS, Impresso, v. 36, p. 95-125, 2011.

MURRAY, Joseph; MERRILL, John P.; HARRISON, J. Hartwell. Renal homotransplantation in identical twins. Journal of the American Society of Nephrology, [s.l.], v. 12, n. 1, p. 201-204, [1955] 2001.

MURRAY, Joseph et al. Prolonged Survival of Human-Kidneys Homografts by Immunosuppressive Drug Therapy. The New England Journal of Medicine, [s.l.], v. 268, n. 24, p. 1.315-1.323, 1963.

NAGY, Judit. A Note on the Early History of Renal Transplantation: Emerich (Imre) Ullmann. American Journal of Nephrology, [s.l.], v. 19, n. 2, p. 346-349, 1999. 
PARRILLA, Pascual; RAMÍREZ, Pablo; RÍOS, Antonio. Perspectiva Histórica de los Trasplantes. In: PARRILLA, Pascual; RAMÍREZ, Pablo; RÍOS, Antonio (org.). Manual sobre Donación y Trasplante de Órganos. 1. ed. Madrid: Arán Ediciones, 2008. p. 35-42.

PUERTA, Carlos Vaquero. Contribución Histórica de Alexis Carrel a la Cirugía Experimental. Real Academia de Medicina y Cirugía de Valladolid, Valladolid, 2006.

QUIRKE, Viviane; GAUDILLIÈRE, Jean-Paul. The era of biomedicine: science, medicine, and public health in Britain and France after the Second World War. Medical History, [s.l.], v. 52, p. 441-452, 2008.

REGGIANI, Andres Horacio. Alexis Carrel the Unknown: Eugenics and Population Research under Vichy. French Historical Studies, [s.l.], v. 25, n. 2, p. 331-356, 2002.

SADE, Robert M. Transplantation at 100 Years: Alexis Carrel, Pioneer Surgeon. Ann Thorac Surg, [s.l.], v. 80, p. 2.415-2.418, 2005.

SILVA, Paulo Rodrigues da. Transplante cardíaco e cardiopulmonar: 100 anos de história e 40 de existência. Revista Brasileira de Cirurgia Cardiovascular, [s.l.], v. 23, n. l, p. 145-152, 2008.

STARZL, Thomas Earl. Personal Reflections in Transplantation. Surgical Clinics of North America, [s.l.], v. 58, n. 5, p. 879-893, 1978.

STARZL, Thomas Earl. Peter Brian Medawar: father of transplantation. Journal of the American College of Surgeons, [s.l.], v. 180, n.3, p. 332-336, 1995.

STEFONI, Sergio et al. The History of Clinical Renal Transplant. J Nephrol, [s.l.], v. 17, p. 475-478, 2004.

TEIXEIRA, Marcelo Weinstein; REZENDE, Cleuza Maria de Faria. Imunossupressão e transplantes: perspectivas atuais e futuras. MEDVEP. Revista Cientifica de Medicina Veterinaria, [s.l.], n. 7, p. 12-16, 2004.

TESSER, Charles Dalcanale. A verdade na biomedicina, reações adversas e efeitos colaterais: uma reflexão introdutória. PHYSIS: Rev. Saúde Coletiva, [s.l.], v. 17, p. 465-484, 2007.

WINKLER, Enno. Ernst Unger: A Pioneer in Modern Surgery. Journal of the History of Medicine and Allied Sciences, [s.l.], v. 37, n. 3, p. 269-286, 1982.

\section{Vitor Jasper}

Doutorando em Antropologia pelo Programa de Pós-Graduação em Sociologia e Antropologia da Universidade Federal do Rio de Janeiro (PPGSA/UFRJ).

Endereço profissional: Programa de Pós-Graduação em Sociologia e Antropologia. Largo de São Francisco de Paula, n. 1, sala 420, Centro, Rio de Janeiro, RJ. CEP: 20051-070.

E-mail:vitorjasper@gmail.com

ORCID: https://orcid.org/0000-0002-4517-3103

\section{Como referenciar este artigo:}

JASPER, Vitor. Entre Experimentos, Controvérsias e Invisibilidades: a constituição do transplante de órgãos como prática terapêutica. Ilha - Revista de Antropologia, Florianópolis, v. 23, n. 3, p. 176-196, setembro de 2021. 